\title{
Psychiatric admission for homeless people: the impact of a specialist community mental health team
}

\author{
Martin Commander, Sue Odell and Sashi Sashidharan
}

\begin{abstract}
The difficulty in achieving good quality community mental health care for homeless people has recelved increasing attention during the last few years. Less consideration has been given to the provision of inpatient care. By comparing data collected before and after its inception, we examined the impact of a specialist community mental health feam for homeless people on 'no fixed abode' admissions in Birmingham. Although the feam was successtully involved in the admission and discharge process in a substantial proportion of cases, many admissions still took place out of hours and involved the police, while discharge was often against medical advice and occurred without follow-up. These findings and their implications for the provision of homeless services are discussed.
\end{abstract}

Considerable problems have been encountered in providing care to homeless people with mental health problems (Health Advisory Service, 1995). In many instances mainstream services have failed to adapt to meet the needs of people who are often not registered with a GP and who regularly move between catchment areas. In districts with high levels of homelessness, specialist community teams have been established (Craig et al, 1995). The service in Birmingham has been demonstrated to be effective in targeting a transient population with severe psychiatric morbidity not in contact with mainstream services (Commander et al, 1997). However, with few exceptions (Whiteley, 1955; Berry \& Orwin, 1966; Herzberg, 1987) little attention has been paid to the provision of in-patient care to homeless people in the UK.

This study evaluates the impact of a specialist community mental health team (CMHT) for homeless people on admissions of people of no fixed abode (NFA) to psychiatric hospitals in Birmingham. It compares admissions before and after the introduction of the service with respect to both the number and characteristics of those admitted as well as the admission pathways and discharge arrangements.

\section{The study}

Birmingham CMHT for the homeless is a multidisciplinary team $(0.5$ whole-time equivalent consultant psychiatrist, three community psychiatric nurses, one social worker and two resettlement officers) working collaboratively with other agencies across the city to provide mental health care to homeless people with severe mental illness. The team does not currently provide in-patient care. Separate weekly rotas of adult consultant psychiatrists operate in the north and south parts of the city (managed by different NHS Trusts) to determine who is responsible for each admission. The NFA rota applies to people who are strictly roofless as well as those recently resident in direct access hostels. The admitting Trust is determined by the location of the patient's previous night's accommodation, or if unavailable their current location (e.g. police station).

All admissions of homeless people to psychiatric hospitals under the NFA rota were identified over one year (1 February 1995 to 31 January 1996) by contacting acute wards weekly by telephone. For all eligible admissions, demographic details and information concerning the admission process were collected from staff and case notes using a proforma designed for the purpose. Further data on discharge and aftercare arrangements were collected from the same source once the patient had left hospital.

The comparison data were collected during the years 1989 to 1992 , prior to the inception of the CMHT for the homeless. At this time the place of admission for homeless people under the NFA rota was determined by a one month in four rotation of psychiatric hospitals in Birmingham, supplemented by a rota of consultants within each unit. Admissions to one of these hospitals during a 4-year period were identified from ledgers kept by medical records. This gave the equivalent of one year of NFA admissions. 
Demographic data and information concerning the episode of in-patient care were obtained retrospectively from the case notes.

\section{Findings}

During the year 1995-96, 91 people (106 admissions) were admitted to hospitals in Birmingham under the NFA rota compared with 87 people (105 admissions) in 1989-92. There were no significant differences between the two samples in terms of gender, age, ethnicity or marital status. The vast majority of patients were single white men under 50 years of age (see Table 1). Schizophrenia was consistently the most common primary diagnosis, with substance use disorders and personality disorders the next most frequent. Also, most patients in both samples had a history of previous admission to psychiatric hospital (see Table 1).

The general hospital (usually the casualty department) and the police/courts remained common sources of referral for admission, while GP referrals were rare in both samples $(7 \%$ in $1995-96,1 \%$ in 1989-92, see Table 2). However, in the 1995-96 survey mental health staff were more often involved in the referral process. The CMHT for the homeless were directly responsible for initiating $21 \%$ of admissions, and a further $10 \%$ of admissions involved people who were currently open to the team. Another notable difference between the two samples was in the

Table 1. Demographic and clinical characteristics (\%)

\begin{tabular}{lcc}
\hline & $1989-92$ & $1995-96$ \\
\hline $\begin{array}{l}\text { Demographic } \\
\text { Gender }\end{array}$ & 79 & 89 \\
Male & 21 & 11 \\
Female & 36 & 47 \\
Age & 57 & 43 \\
Up to 30 years & 7 & 9 \\
$31-50$ years & & \\
$>50$ years & 5 & 6 \\
Ethnicity & 8 & 11 \\
Asian & 88 & 83 \\
Black & & \\
White & 68 & 83 \\
Marital status & 12 & 7 \\
Single & 21 & 10 \\
Married & & \\
Divorced/widowed & & \\
Clinical & 39 & 42 \\
Primary diagnosis & 26 & 19 \\
Schizophrenia & 23 & 17 \\
Drugs/alcohol & 12 & 22 \\
Personality disorder & 91 & 83 \\
Other \\
Previous admission & & \\
\hline
\end{tabular}

use of the Mental Health Act; only one in ten of the 1989-92 sample compared with almost half of the 1995-96 sample were admitted compulsorily (see Table 2). Of all the admissions in the later study, $37 \%$ occurred out of normal working hours (i.e. 9am to $5 \mathrm{pm}$, Monday to Friday). Comparative data were unavailable for 1989-92 admissions.

The lengths of hospital stay were similar in the two samples (the majority being discharged within four weeks of admission). A substantial minority of patients in both surveys were discharged against medical advice but this was significantly lower in 1995-96 (see Table 2). Furthermore, although less than half the patients in either survey had any follow-up by mainstream services, the proportion receiving aftercare was significantly higher for the 199596 sample (see Table 2). This was due to the fact that over a third continued to be seen by the CMHT for the homeless.

Despite the inception of the specialist service, deficits clearly remained in the provision of mental health care to homeless people entering and leaving hospital. This led us to examine whether there were any differences in the admission experiences of homeless people with schizophrenia (the target client group for the homeless team) compared with those with other diagnoses during 1995-96 (see Table 2). The former were found to be more likely to access inpatient care between the hours of 9 am and $5 \mathrm{pm}$ and through mental health staff. In contrast, almost half the patients with non-psychotic disorders were admitted outside normal working hours $\left(49 \%\right.$ compared with $22 \%$; $\chi^{2}=6.8$; $P=0.0009$ ) and via the general hospital. People with schizophrenia were also more likely to be detained compulsorily, had longer lengths of stay in hospital and more often received follow-up (especially by the CMHT for the homeless) than those with other diagnoses.

\section{Comment}

Both studies used the NFA rota as their sampling frame. The criteria for admission under the rota are broad and their interpretation may have varied between the studies (Cowan \& MacMillan, 1996). Also, the 1989-92 study sampled NFA admissions from medical records whereas the 1995-96 study approached ward staff directly. These differences may have introduced bias and indicate the need for caution when drawing conclusions from our findings.

The number of homeless people admitted, as well as their demographic and clinical characteristics, remained remarkably similar during the period before and after the introduction of the CMHT for homeless people; young single white 
Table 2. Admission process and discharge arrangements (\%)

\begin{tabular}{|c|c|c|c|c|c|c|}
\hline & $\begin{array}{l}\text { 1989-92 } \\
\text { Total }\end{array}$ & $\begin{array}{l}\text { 1995-96 } \\
\text { Total }\end{array}$ & & $\begin{array}{l}\text { 1995-96 } \\
\text { Schizo- } \\
\text { phrenia }\end{array}$ & $\begin{array}{l}1995-96 \\
\text { Other } \\
\text { diagnoses }\end{array}$ & \\
\hline Source & & & $\chi^{2}=7.4 ; P=006$ & & & $\chi^{2}=9.9 ; P=0.02$ \\
\hline General hospital & 38 & 29 & & 15 & 16 & \\
\hline Police/courts & 26 & 20 & & 24 & 41 & \\
\hline Mental health staff & 10 & 27 & & 37 & 19 & \\
\hline Other & 26 & 25 & & 24 & 24 & \\
\hline $\begin{array}{l}\text { Use of Mental Health Act } \\
\text { Length of stay }\end{array}$ & 11 & 48 & $\begin{array}{l}\chi^{2}=23.8 ; P<0.0001 \\
\text { NS }\end{array}$ & 69 & 32 & $\begin{array}{l}\chi^{2}=13.6 ; P=0.0002 \\
\chi^{2}=13.1 ; P=0.004\end{array}$ \\
\hline up to 1 week & 31 & 23 & & 10 & 29 & \\
\hline $1-4$ weeks & 34 & 34 & & 26 & 41 & \\
\hline 1-3 months & 18 & 29 & & 45 & 19 & \\
\hline$>3$ months & 17 & 14 & & 19 & 10 & \\
\hline Discharge against advice & 37 & 20 & $\chi^{2}=5.3 ; P=0.02$ & 26 & 17 & \\
\hline Any follow-up & 46 & 72 & $\chi^{2}=12.0 ; P=0.0005$ & 89 & 62 & $\chi^{2}=8.4 ; P=0.004$ \\
\hline Homeless team & - & 37 & & 65 & 20 & \\
\hline Other mental health staff & 37 & 32 & & 24 & 36 & \\
\hline Addiction services & 9 & 3 & & - & 6 & \\
\hline
\end{tabular}

men with schizophrenia predominated in both samples. Even though it was not identified as a team goal, one might have expected the introduction of the new community service to reduce requirements for in-patient care. While this was true in individual cases, it is likely that any decrease was offset by a rise in admissions of people who would otherwise have been 'missed' by mental health services as well as from the growing number of homeless people in general. The dramatic increase in the use of the Mental Health Act (to a level more than five times the national average; Wing, 1994) is also consistent with the homeless team addressing the needs of people who in the past would have evaded services. However, a heightened threshold for admission and increasing use of compulsory treatment has been a recent feature of many inner city services faced with scarce in-patient resources. The fact that the number of NFA admissions has at least remained stable in this climate suggests that the team is effectively ensuring access to limited hospital provision for this marginalised client group.

The impact of the team on NFA admissions was undoubtedly hindered by the fact that it was only operational 9am to 5pm. Monday to Friday, many admissions (including of open cases) occurring out of hours. Nevertheless, the homeless team did appear to play an important role in facilitating admission to hospital. Many admissions were directly initiated by the team and a substantial proportion of the remainder were of people already known to the specialist homeless service. The fact that around a quarter of admissions continued to come via the police or courts emphasises the importance of court diversion and diversion at point of arrest schemes in providing services to homeless people, and the need for close links between specialist homeless and forensic teams. Similarly, the substantial numbers admitted through A\&E departments points to the value of educating casualty staff about the availability of local services for this population.

As with domiciled patients, few homeless people in either survey remained in hospital longer than three months and over half were discharged within four weeks $(57 \%$ in the 1995 96 sample compared with $60 \%$ in a local inpatient survey: Sashidharan et al, 1995). The impact of the homeless service on improving follow-up was evident, the team being directly involved in the provision of aftercare in over a third of cases. Also, fewer patients were discharged against medical advice.

The patients who seemed to gain least from the inception of the CMHT for the homeless were those with non-psychotic disorders, predominantly personality and substance use disorders. As intended, the team successfully focused its efforts on homeless people with schizophrenia. However, the experience of other groups, from the moment of referral to hospital through to the provision of aftercare, was far less satisfactory. People with personality disorders and substance use problems are excluded from many services, including those targeting homeless people (Craig et al, 1995) and further consideration needs to be given as to how best to assist them.

\section{Acknowledgements}

We thank Drs Hosty and Harrison for permission to use their data on NFA admissions for 
1989-1992, and Ms Alison Reeves for her assistance in collecting data on the 1995-96 sample.

\section{References}

BERRY, C. \& ORWIN, A. (1996) No fixed abode: a survey of mental hospital admissions. British Journal of Psychiatry. 112, 1019-1025.

COMmANDER, M., Odell S. \& SASHIDHARAN, S. (1997) Birmingham community mental health team for the homeless. Psychiatric Bulletin, 21, 74-76.

Cowan, C. \& Macmillan, F. (1996) No fixed abode-its definition in clinical practice. Joumal of Mental Health. 5. 161-165.

Craig, T., Bayuss, E., KLein, O., et al (1995) The Homeless Mentally II Initiative: An Evaluation of Four Clinical Teams. London: Department of Health.

Health Advisory Service (1995) People Who Are Homeless: Mental Health Services A Place in Mind. London: HMSO.
HERZBERG, J. L. (1987) No fixed abode. A comparison of men and women admitted to an East London psychiatric hospital. British Journal of Psychiatry. 160. 621-627. SashidHaRAn, S. P., Commander, M. J., ODELl, S., et al (1995) West Birmingham Psychiatric Epidemiology Research Project. Report 1: Use of Specialist Mental Health Services. Birmingham: University of Birmingham.

WHITELEY, J. S. (1955) Down and out in London: menta illness in the lower social groups. Lancet, 2, 608-610.

WING, J. K. (1994) Mental illness. In Health Care Needs Assessment (eds A. Stevens and J. Raftery). pp. 202 304. Oxford: Radcliffe Medical Press.

*Martin Commander, Sue Odell and Sashi Sashidharan, University of Birmingham, Department of Psychiatry. Northern Birmingham Mental Health (NHS) Trust, Academic Unit, 71 Fentham Road, Erdington, Birmingham B23 6AL

*Correspondence

\section{Prevention of Anxiety and Depression in Vulnerable Groups}

\section{Joanna Murray}

The scope of this review, commissioned by the Department of Health, is the common mental disorders of anxiety and depression occurring in adults in the community. It considers the possibilities for prevention in primary care. This combination of basic conceptual and research information provides a practical framework of preventive strategies for the primary care team. Social factors in aetiology are examined in detail, and epidemiological data is used to consider vulnerability factors and to identify high risk groups. There is also a thorough review of risk for common mental disorders. £7.50, 112pp., 1995, ISBN 0902241877

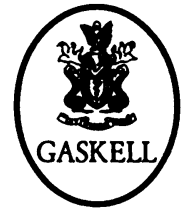

Gaskell books are available from good bookshops and from the Publications Department, Royal College of Psychiatrists, 17 Belgrave Square, London SW1X 8PG (Tel. +44(0)171 235 2351, extension 146).

The latest information on College publications is available on the INTERNET at: http://www.demon.co.uk/rcpsych/ 